\section{Analysis of Anæesthetic Mixtures by Gas Chromatography}

DURING anæsthesia, and in respiratory research, there is a need to analyse mixtures of permanent gases and organic vapours on a routine basis. Physical methods are being increasingly used for this type of work, but the equipment required tends to become complex when the analysis of several components is desired. Chromatographic analysis is discontinuous in nature, but, provided that this can be tolerated, the use of gas chromatography offers several ad. vantages of which simplicity and versatility are the most important.

For the separation of oxygen and nitrogen we have employed a column 12 in. long and $\frac{1}{4}$ in. internal diameter packed with 52-60 B.S. mesh Linde $5 A$ molecular sieve at room temperature. Samples can be analysed at 30 -sec. intervals.

Carbon dioxide and nitrous oxide are commonly encountered in respired anæsthetic mixtures since the majority of anestheties are based on nitrous oxide and oxygen. None of the common adsorbents, such as silica gel, alumina and charcoal, will give an adequate separation of these gases. However, we have found that a G.L.C. column $24 \mathrm{ft}$. long by $\frac{1}{4}$ in. internal diameter packed with $28 \cdot 6$ per cent of propylene carbonate on 52-60 B.S. mesh 'SIL-O-CEL'

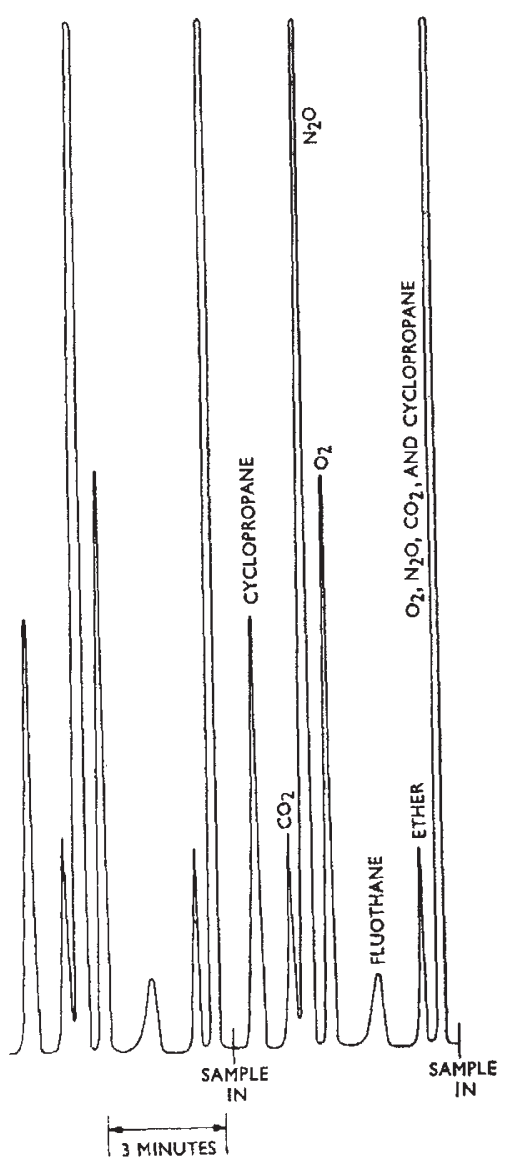

Fig. 1. Chromatogram of a respired anxsthetic mixture, Column $1,20 \mathrm{ft} . \times$ in. 20 per cent dimethyl sulphoxide on 52-60 mesh 'SIL-O-CEL' at $20^{\circ} \mathrm{C}$.; inlet pressure $280 \mathrm{~mm}$. mercury. Column 2, $2 \mathrm{ft}$. $\times{ }^{\frac{1}{4}}$ in. 15 per cent dinonyl phthalate on 52-60 mesh 'SIL-0-CEL' at $75^{\circ} \mathrm{C}$.; inlet pressure $40 \mathrm{~mm}$ mercury. Flow-rate, $30 \mathrm{ml}$. $/ \mathrm{min}$. $\mathrm{H}_{2}$ in both columns firebrick will separate these gases at room temperature. A mixture of oxygen, carbon dioxide and nitrous oxide can be analysed in about $2 \frac{1}{2} \mathrm{~min}$. on such a column. By overlapping the samples the analysis may be repeated every $2 \mathrm{~min}$. Recently we have found that dimethyl sulphoxide is an even better stationary liquid for this work. A 20 -ft. by $\frac{1}{4}$-in. column containing 20 per cent of dimethyl sulphoxide on 52-60 mesh 'SIL-O-CEL' at $20^{\circ} \mathrm{C}$. will separate a mixture of oxygen, nitrous oxide and carbon dioxide in $1 \mathrm{~min}$.

When ether and fluothane are present, a 2 -ft. by $\frac{1}{4}$-in. column containing 15 per cent of dinonyl phthalate on firebrick is used in parallel with the dimethyl sulphoxide column. Automatic valves ${ }^{1}$ inject different-sized samples simultaneously into both columns. The dinonyl phthalate column is heated to $75^{\circ} \mathrm{C}$, allowing the light gaseous components to pass through unresolved but retaining ether and fluothane long enough to give complete separation. The gases and vapours from the two columns pass through opposite channels of a thermistor thermal conductivity detector. The recorder in the bridge circuit is modified so that a negative signal actuates a reversing switch and consequently all the peaks on the recorder chart are in the same direction. Fig. 1 shows the separation of a respired anæsthetic mixture analysed in this way in approximately $4 \frac{1}{2} \mathrm{~min}$.

We wish to thank Prof. R. F. Woomer, of the Royal College of Surgeons, and the Directors of "Shell" Research, Ltd., for their encouragement, and for permission to publish this communication. We also wish to thank colleagues at the Koninklijke/ Shell-Laboratorium, Amsterdam, who suggested the use of dimethyl sulphoxide as a stationary liquid.

E. R. Adlard

"Shell" Research, Ltd.,

Thornton Research Centre, Chester.

D. W. Hilu

Research Department of Anæsthetics, Royal College of Surgeons of England, London, W.C.2.

${ }^{2}$ Hill, D. W., and Hook, J. R. (unpublished work).

\section{RADIATION CHEMISTRY}

\section{Radiative Life-time of the Pyrene Dimer and the Possible Role of Excited Dimers in Energy Transfer Processes}

THE absorption spectra of eertain dye solutions exhibit a marked dependence on concentration over a range in which the corresponding fluorescence spectrum remains unchanged; this is attributed to absorption by non-fluorescent dimeric complexes at higher concentration which reduces the overall fluorescence yield of the solution ${ }^{1}$. The relative intensities of absorption by the dye in its monomeric and dimeric forms suggest that the radiative lifetimes of the corresponding excited species are both of the order of $10^{-8}-10^{-8}$ sec. (ref. 2).

On the other hand, Förster and Kasper ${ }^{3}$ have observed that, whereas the absorption spectrum remains unchanged, the violet fluorescence of dilute solutions of pyrene is replaced by a blue emission at higher concentrations; in this case the excited dimer responsible for the blue fluorescence is formed 